\title{
Neurohormonal consequences of diuretics in different cardiovascular syndromes
}

\author{
M. BURNIER AND H. R. BRUNNER
}

Division of Hypertension, University Hospital, and Policlinique Médicale Universitaire, Lausanne, Switzerland

KEY WORDS: Diuretics, renin, angiotensin II, vasopressin, atrial natriuretic peptide, endopeptidase inhibitors.

Diuretics have long been used to lower blood pressure in hypertensive patients or to control body fuid and electrolyte homeostasis in diseases such as congestive heart failure, chronic renal failure or cirrhosis. The initial response to diuretics is a negative sodium and fluid balance. The diuretic-induced loss of salt and water activates several hormonal systems such as vasopressin, the renin-angiotensin-aldosterone system or the sympathetic nervous system which tend to compensate for the changes in sodium and water balance. This neurohormonal response may have important clinical implications. Thus, the activation of the renin-angiotensin-aldosterone cascade appears to be partially responsible for the flat dose-blood pressure response curve of thiazides in hypertensive patients. It may also be responsible for the difference between responders and non-responders to diuretic therapy and for the development of side-effects such as hypokalaemia, metabolic alkalosis or hyponatraemia. There are several ways to prevent the undesirable consequences of the neurohormonal responses to diuretics. The first is to use low doses of these agents. It is also possible to combine them with agents that block the activity of the renin-angiotensin-aldosterone system such as $A C E$ inhibitors or in combination with drugs that reduce aldosterone secretion such as calcium antagonists. The development of drugs able to enhance urinary sodium excretion and to reduce simultaneously the activity of the renin-angiotensin-aldosterone system may offer a new interesting alternative. This might perhaps be achieved in the future with the administration of neutral endopeptidase inhibitors which interfere with the enzymatic degradation of atrial natriuretic peptide.

\section{Introduction}

Diuretics have been used for several decades to lower blood pressure in hypertensive patients or to control sodium and volume balance in diseases such as congestive heart failure, chronic renal failure or liver cirrhosis. The changes in systemic haemodynamics and the modifications of fluid and electrolyte excretion induced by the acute or chronic administration of diuretics have been well characterized ${ }^{[1,2]}$. The initial response to diuretic therapy is a negative sodium and fluid balance, followed by a decrease in plasma volume and cardiac output leading to a fall in blood pressure. The acute reduction in blood pressure is associated with a compensatory rise in calculated peripheral vascular resistance.

During long-term diuretic treatment, however, extracellular fluid, plasma volumes and cardiac output tend to return to control values, whereas peripheral vascular resistance decreases ${ }^{[3]}$. Blood pressure therefore remains low despite the normalization of cardiac output. The mechanisms whereby peripheral vascular resistance is reduced during prolonged diuretic administration are still not completely understood. The vasodilating effect of diuretics may be mediated directly by a reduction in vascular reactivity to vasoconstrictor mechanisms due to a decrease in intracellular sodium and calcium concentrations in vascular smooth muscle cells ${ }^{[4]}$. This would also result in a decrease in vascular responsiveness to vasocontrictor agents such as angiotensin II or catecholamines ${ }^{14,5]}$. Diuretics may also promote the synthesis of vasodilating hormones such as prostaglandins or kallikreins $\mathrm{s}^{[4]}$.

Correspondence: Dr M. Burnier, MD, PD, Policlinique Médicak Universitarre, Av. Cesar-Roux 19, 1005 Lausanne, Swilzerland.
The diuretic-induced salt and water loss activates several neurohormonal systems normally involved in the regulation of body fluid and electrolyte balance. Depending on the diuretic dosage, a series of counterregulatory mechanisms will be triggered which will tend to offset the benefits of these agents. These include an activation of the renin-angiotensin-aldosterone system, vasopressin, prostaglandins and the sympathetic nervous system. This hormonal response has important clinical consequences as it modulates the haemodynamic and renal effects of diuretics. Moreover, it may be responsible for the development of side-effects. The purpose of this review is to discuss the consequences of the neurohormonal response to diuretic therapy and to analyse the different possibilities to prevent them in various cardiovascular syndromes.

\section{Physiological regulation of body fluid and electrolyte balance}

The kidneys are responsible for the regulation of salt and water balance and hence contribute to blood pressure maintenance. Several neurohormonal systems participate in this homeostatic process by modulating renal sodium and water handling and by eliciting systemic and renal haemodynamic changes. Thus, the sympathetic nervous system promotes renal sodium reabsorption in the renal proximal tubule and increases the systemic blood pressure via the vasoconstrictor properties of norepinephrine. Furthermore, humoral factors such as renin via angiotensin Il and aldosterone increase sodium reabsorption in the proximal and distal tubules. Angiotensin II is also a 
strong vasoconstrictor which plays a major role in the regulation of glomerular filtration rate. Angiotensin II increases both the efferent and afferent arteriolar vascular resistance and thereby controls the glomerular capillary hydrostatic pressure ${ }^{[6]}$. Angiotensin II also reduces the glomerular ultrafiltration coefficient and the effective glomerular surface area ${ }^{[6-8]}$. Another important humoral factor is vasopressin whose osmotic and non-osmotic release allows control of renal water excretion in response to changes in sodium and water homeostasis. Vasopressin also exhibits a strong vasopressor potential.

The effect of these vasoconstrictor and salt and water retaining hormones is generally opposed by that of vasodepressor and natriuretic hormones such as prostaglandins, kinines or atrial natriuretic peptide. Atrial natriuretic peptide (ANP) effectively antagonizes the renin-angiotensin system. Indeed, ANP decreases renin secretion, increases urinary sodium and water excretion and lowers blood pressure ${ }^{[9,10]}$. It also inhibits angiotensin II-induced vasoconstriction. Moreover, ANP favours the shift of fluid out of the intravascular compartment which is reflected by increasing haematocrit ${ }^{[12]}$. Thus, there is a multifactorial control system which guarantees water and sodium balance and blood pressure maintenance. In such a system not all components have the same weight, and the development of specific antagonists has facilitated the determination of the relative contribution of each of these systems.

\section{NEUROHORMONAL RESPONSE TO SALT DEPLETION}

Diuretics enhance renal sodium excretion at different sites along the renal tubules, and the renin-angiotensin system plays a major role in the maintenance of sodium balance. A close relationship exists between a reduction in sodium balance induced by salt depletion or diuretics and the response of renin secretion ${ }^{[13,14]}$. When human subjects or animals are changed to a low sodium diet, a rapid stimulation of the renin-angiotensin system reduces urinary sodium excretion and maintains circulatory homeostasis. Indeed, salt-depleted animals pretreated with a converting-enzyme inhibitor are unable to prevent renal sodium loss and maintain an adequate blood pressure $^{(15)}$. A similar observation has been made in human subjects salt-depleted by a low sodium diet $(10 \mathrm{mmol}$ sodium/day) for 6 days together with a diuretic on the initial two days and infused with the angiotensin II antagonist, saralasin ${ }^{[16]}$. Saralasin had no effect on blood pressure in the supine position, but these subjects became severely hypotensive upon assuming an upright position. All had accumulated sodium losses over the 6 days exceeding $200 \mathrm{mmol}^{[16]}$.

The crucial role of the renin-angiotensin system in titrating sodium excretion has also been shown by the studies of Hall et al.$^{11 \pi}$ who varied sodium intake over a wide range in three groups of dogs: one control, one with a fixed, low dose infusion of angiotensin II and one which converting enzyme was inhibited. All three groups of animals were able to raise their urinary sodium excretion in response to the enhanced sodium intake. However, only the control group could do it without a marked change in mean arterial pressure. These experiments demonstrate that whenever the activity of the reninangiotensin system is fixed, at a high or at a low level, major changes in blood pressure are needed to adapt sodium excretion to salt intake.

In fact, the neurohormonal response to salt depletion or diuretics, and in particular the renin-response, may sometimes be such that blood pressure increases or fails to decrease. This phenomenon has been reported in patients with congestive heart failure in whom a transient increase in blood pressure has been found after acute administration of furosemide ${ }^{[18]}$.

\section{NEUROHORMONAL RESPONSE TO CHANGES IN WATER} BALANCE

The second important property of diuretics is to increase fluid excretion. The polypeptide hormone, vasopressin, has long been known to exert an antidiuretic effect and to have a direct vasoconstrictor action on the arterioles of the peripheral circulation. The results of several animal studies have suggested a significant role for vasopressin in maintaining blood pressure during volume depletion. In these experiments, specific vasopressin pressor antagonists, which are synthetic analogues acting as competitive inhibitors of vasopressin at the vascular (V1) receptor, were used ${ }^{[19-21]}$. In our laboratory, we attempted to evaluate the respective role of vasopressin and the renin angiotensin system in maintaining blood pressure during water deprivation ${ }^{[2]}$. For this purpose, two groups of rats were water-deprived for $48 \mathrm{~h}$. One group was pretreated with an ACE inhibitor, to prevent angiotensin 11 generation and the other vehicle-treated group served as control. Following $48 \mathrm{~h}$ dehydration, animals with an intact renin angiotensin system exhibited a blood pressure of $132 \mathrm{mmHg}$ compared with $105 \mathrm{~mm} \mathrm{Hg}$ for the group of rats with virtually no circulating angiotensin II. Plasma vasopressin levels were increased sevenfold after $48 \mathrm{~h}$ dehydration. Nevertheless, the vascular antagonist of vasopressin reduced blood pressure by a mere $6 \mathrm{mmHg}$ in the presence of an intact renin angiotensin system. In contrast, in the absence of angiotensin II, a marked decrease in blood pressure $(-17 \mathrm{~mm} \mathrm{Hg}$ ) was observed after administration of the vasopressin antagonist. These results suggest that when water deprivation becomes severe enough to threaten volume homeostasis and thereby normal blood pressure control, the compensatory rise in renin secretion becomes the predominant factor in blood pressure regulation. Only when the renin angiotensin system is blocked does vasopressin exert a greater effect. This supports the idea that a hierarchy exists among the different compensatory mechanisms.

Taken together, these observations also demonstrate that among the various neurohormonal factors physiologically involved in the response to changes in sodium and water intake or excretion, the reactivity of the renin angiotensin system plays a leading role in maintaining blood pressure within physiologically acceptable limits. For the clinician, this response will be particularly important when pharmacological interventions such as the administration of diuretics or other antihypertensive 


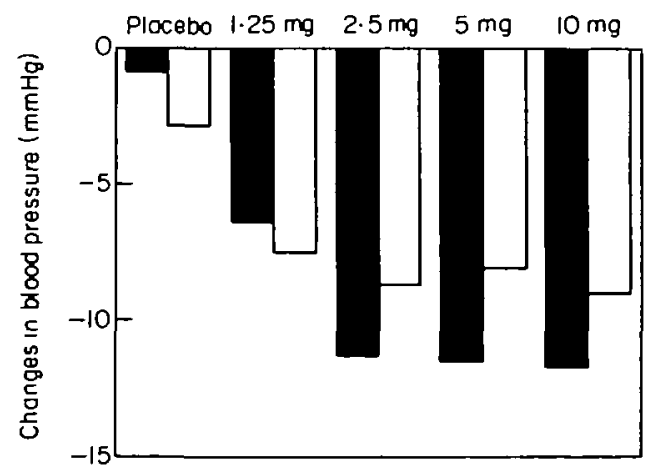

Figure I Variations in blood pressure in 257 patıents with essential hypertension treated for 4 weeks with increasing doses of bendrofluazde. $\square=$ systolic blood pressure; $\square=$ diastolic blood pressure. (Adapted from Carlsen et al. ${ }^{(27)}$ ).

agents, are used to lower blood pressure in hypertensive patients or to increase urinary sodium and water excretion in diseases associated with sodium retention.

\section{NEUROHORMONAL RESPONSE TO DIURETICS IN HYPERTENSION}

Diuretics have long been established as first-line antihypertensive therapy. The blood pressure reduction obtained with the various types of diuretics is quite comparable, although under certain circumstances diuretics with a very rapid and short-lasting effect, such as the loop diuretic furosemide, tend to be less effective. Most of the antihypertensive effect of thiazide- or potassium-sparing diuretics can be achieved with relatively low doses ${ }^{[22-24]}$. Figure 1 presents the changes in systolic and diastolic blood pressure obtained in a recent study with increasing doses of the thiazide diuretic, bendrofluazide ${ }^{[23]}$. The diuretic was administered to 257 patients with mild to moderate hypertension for 12 weeks after a 6 week placebo period. After 4 weeks of treatment, the maximal reduction of blood pressure was achieved with $2.5 \mathrm{mg}$ only. Higher doses caused more pronounced adverse biochemical effects including deterioration of patients lipid profile. A similar observation has been made by Jeunemaitre ef $a l^{[24]}$ who analysed the results obtained in 182 patients treated with spironolactone alone during a mean follow-up period of 23 months. The maximal decrease in diastolic blood pressure was seen with doses ranging around $75 \mathrm{mg}$. day ${ }^{-1}$. However, the incidence of gynecomastia increased progressively to exceed $50 \%$ at the highest dose of spironolactone used, whereas this sideeffect occurred infrequently at the optimal therapeutic range, i.e. $<75 \mathrm{mg}$. day ${ }^{-1}$.

The neurohormonal response to diuretic therapy may be partially responsible for this apparently flat doseresponse curve. The regulatory mechanisms seem to vary from person to person. If some hypertensive subjects do not respond to diuretics with a fall in blood pressure, it may be due to a more vigorous angiotensin II-induced vasoconstriction in these patients. To support this hypothesis, several investigators have shown that nonresponders to diuretics frequently exhibit higher plasma renin values and exaggerated aldosterone secretion compared with patients who respond well ${ }^{[25.14]}$. Moreover, during severe sodium restriction i.e. in the presence of an activated renin angiotensin system, thiazides lack any substantial additional effect on blood pressure ${ }^{[26]}$. Furthermore, administration of an angiotensin II antagonist or of an angiotensin converting enzyme inhibitor has been shown to potentiate the hypotensive effects of diuretics $^{[27,28]}$. In heart failure patients, enalapril has been reported to abolish the increases in plasma angiotensin II and aldosterone normally observed after furosemide, and to attenuate the rise in plasma catecholamines ${ }^{[29]}$. However, the potentiation of the diuretic and natriuretic effects of diuretics by ACE inhibitors are observed only if glomerular filtration rate remains stable; a significant reduction in glomerular filtration rate may indeed completely blunt the renal effects of both drugs ${ }^{[29,30]}$

\section{Consequences of the neurohormonal response to diuretics}

The compensatory activation of counter-regulatory mechanisms has several clinical implications, beside the fact that they limit the hypotensive response of drugs. In the case of diuretics, the renin response is also the source of side-effects. Thus, hypokalaemia and metabolic alkalosis develop in response to aldosterone secretion as more sodium is presented to the distal tubule, where it is exchanged for potassium and hydrogen. Hyperuricaemia frequently occurs as a consequence of the increased renal proximal reabsorption which compensates for the sodium losses.

Blood pressure control is an important factor in reversing left ventricular hypertrophy, but not all antihypertensive agents induce regression of left ventricular hypertrophy despite adequate control of blood pressure. It has been postulated that reflex sympathetic stimulation and activation of the renin angiotensin system may be responsible for maintaining hypertrophy in the face of reduced systemic blood pressure. There is increasing evidence that vasoconstrictive substances, such as angiotensin II, vasopressin, catecholamines or endothelin act as growth promoters and favour the development of hypertrophy or hyperplasia in vitro ${ }^{[31]}$. In contrast, vasodilatory substances, such as atrial natriuretic peptide or prostaglandins, exert growth inhibitory effects.

Reversal of left ventricular hypertrophy during diuretic therapy has been extensively studied and reviewed ${ }^{[32]}$. A reduction in left ventricular mass during diuretic therapy has been found in six studies but little or no effect of these agents on ventricular hypertrophy in five reports. As discussed above, the neurohormonal response to diuretic treatment may have played a role in the lack of regression of left ventricular hypertrophy either directly via a growth promoter effect of angiotensin II, vasopressin and norepinephrine or indirectly by blunting the blood pressure fall. Interestingly, a regression of hypertrophied cardiac muscle was almost always obtained when diuretics were combined with sympatholytic agents such as methyldopa or alpha-adrenergic blockers, or with beta-blockers, which, in addition, inhibit renin secretion ${ }^{[32 !}$. 
Neurohormonal response to diuretics in sodium retaining states

Diuretics are commonly used to increase renal sodium and water excretion in diseases associated with sodium retention, such as congestive heart failure, cirrhotic liver disease, and the nephrotic syndrome. In these clinical situations, resistance to diuretic therapy is often encountered and larger doses of diuretics are sometimes needed to achieve a natriuretic response. Several mechanisms are involved in this drug-resistance, including changes in renal haemodynamic or decreases in drug delivery into the urine ${ }^{[33]}$. One important factor, however, appears to be an increased renal proximal reabsorption of solutes mediated in part by the renal effect of the neurohormonal responses. The common characteristic of these sodiumretaining states resides in a decrease in effective arterial blood volume which leads to an activation of the reninangiotensin system, vasopressin, prostaglandins and the sympathetic nervous system ${ }^{[34]}$. This hormonal response causes renal vasoconstriction and favours sodium reabsorption in the proximal tubule. Hence, the efficacy of diuretics is attenuated because sodium delivery to the sites of action of thiazides, loop diuretics and potassium sparing diuretics i.e. the late proximal and the distál tubules, is reduced.

The use of diuretics in these diseases will sometimes reinforce the neurohormal response and may favour the development of undesirable effects. This is particularly true when the disease has progressed to a point where compensatory mechanisms are crucial for the maintenance of blood pressure. Thus, in patients with severe congestive heart failure (NYHA class III to IV), the acute intravenous administration of furosemide has been shown to increase plasma norepinephrine and vasopressin levels and to raise plasma renin activity ${ }^{[18]}$. This neurohormonal stimulation increases blood pressure and peripheral vascular resistance and causes a transient myocardial dysfunction. The performance of the heart may therefore be transiently reduced by the use of loop diuretics.

Dilutional hyponatremia is an important complication of diuretic therapy which has been reported to predict survival in patients with congestive heart failure. It is often encountered in patients receiving large doses of loop diuretics or a combination of thiazides and potassiumsparing diuretics. In this situation, water is retained in excess to sodium in response to the activation of vasopressin and the renin-angiotensin and sympathetic nervous systems. The role of the neurohormonal response in the development of this complication is emphasized by the fact that dilutional hyponatremia can be reversed within a few days upon administration of an ACE inhibitor which blocks the renin-angiotensin system and reduces sympathetic drive and vasopressin release ${ }^{35,36]}$.

\section{Prevention of the neurohormonal response to diuretics}

There are several approaches to prevent the deleterious effects of the neurohormonal response to diuretics. As
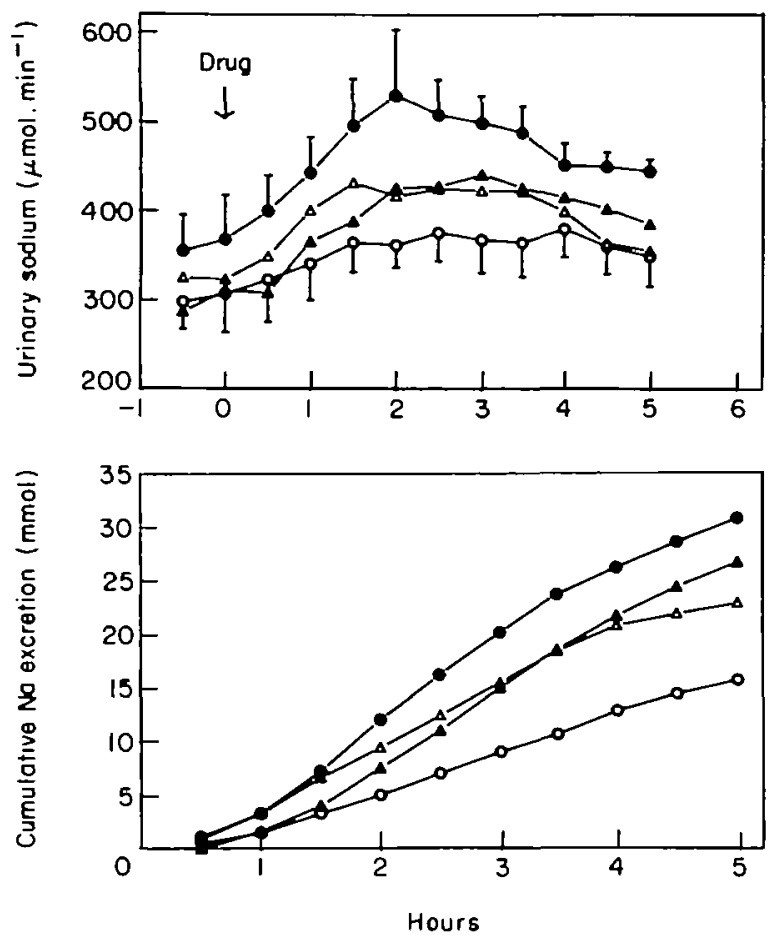

Figure 2 Natriuretic effect of increasing doses of $\mathrm{SCH} 34826$, an inhibitor of atrial natriuretic peptide degradation, in eight healthy salt-loaded volunteers. The cumulative sodium excretion expresses the cumulative amount of sodium excreted after substraction of the baseline elimination of sodıum during the time of observation. (Reproduced with permission ${ }^{(\mu T)}$ ).

mentioned earlier, the activation of counter-regulatory mechanisms depends on the severity of the salt and water depletion induced by these agents. The use of low doses of diuretics is therefore an effective and easy way to reduce the hormone-mediated side effects of these agents. Moreover, it has been clearly demonstrated that thiazides or potassium-sparing diuretics are effective antihypertensive drugs at relatively low doses and that a dose increment does not result in an increased efficacy ${ }^{[23.24]}$.

Another effective approach is to block the activity of the renin-angiotensin system. Many studies have shown that angiotensin converting enzyme inhibitors, or angiotensin II antagonists, potentiate the blood pressure lowering effect of diuretics by blunting the compensatory rise in angiotensin II and aldosterone. For this reason, the association of an ACE inhibitor with a diuretic has become a useful combination in the treatment of hypertension or congestive heart failure. It is important to note, however, that this potentiation may be absent if blood pressure is reduced to below the autoregulation capacity of the kidneys, thereby leading to a fall in glomerular filtration.

Calcium antagonists may also interfere with the activity of the renin-angiotensin system. Indeed, nitrendipine has been shown to blunt the rise in aldosterone secretion elicited by the infusion of angiotensin $\mathrm{II}^{[37]}$. Moreover, a blunting of the angiotensin II-induced pressor response and aldosterone secretion has been demonstrated in 
hypertensive subjects during verapamil therapy ${ }^{[38]}$. In a recent study, nitrendipine has been shown to blunt the bumetanide-induced increase in plasma aldosterone without affecting the renin response in hypertensive patients ${ }^{[39]}$. In a group of six patients, the natriuretic effect of nitrendipine was additive to that of bumetanide but a clear potentiation was not observed.

Since resistance to diuretics in sodium-retaining states is due essentially to an increased renal proximal reabsorption of solutes, it might be expected that coadministration of an agent inhibiting proximal reabsorption may restore the sensitivity to diuretics. There are few, if any, studies that have addressed this question. Brater has reported, however, that administration of acetazolamide to some furosemide-resistant patients caused a parallel upward shift of the dose-response curve but not a normalisation of the right-shifted curve ${ }^{[33]}$.

In the future, it may become possible to use diuretics that increase urinary sodium and water excretion and simultaneously reduce the activity of the renin-angiotensin system. Atrial natriuretic peptides (ANP) have been shown to promote sodium and water excretion and to decrease plasma renin activity, thereby antagonizing the renin-angiotensin system ${ }^{[9,10]}$. Since the early characterization of the physiological and pharmacological effects of atrial natriuretic peptides in animals and humans, several drugs have been developed which reduce ANP degradation by inhibiting its enzymatic metabolism via the neutral endopeptidase ${ }^{[40-42]}$. These drugs lower blood pressure in several animal models of hypertension and particularly in the volume-dependent DOCA-hypertensive rat ${ }^{[43]}$. In normal subjects, neutral endopeptidase inhibitors increase plasma or urinary ANP levels and exert natriuretic effects (Fig. 2) (44-46] $^{[40 w e v e r, ~ t h e i r ~ a b i l i t y ~ t o ~ r e d u c e ~}$ blood pressure in patients with hypertension remains to be demonstrated. Inhibitors of ANP degradation have also been shown to increase renal sodium excretion in patients with congestive heart failure or cirrhosis of the liver ${ }^{[47,48]}$. Thus, inhibition of ANP degradation may become a very useful tool in the management of patients with sodium retaining diseases. These drugs may have the advantage of potentiating the effects of a 'natural' diuretic i.e. ANP, which enhances sodium excretion without activating major regulatory mechanisms.

\section{Conclusion}

The loss of sodium and fluid induced by the administration of diuretics triggers several neurohormonal responses which have important clinical implications. The regulatory mechanisms activated by diuretics, and in particular the renin response, may limit the hypotensive effects of these agents and contribute to the development of side-effects such as hypokalaemia or metabolic acidosis. To prevent the renin response or activation of vasopressin or of the sympathetic nervous system, diuretics should be used at lower doses or can be combined with drugs such as converting enzyme inhibitors or perhaps calcium channel blockers. The development of drugs able to enhance sodium excretion and to reduce simultaneously the activity of the renin angiotensin system might offer a new alternative to treat hypertensive patients or patients with sodium retaining states. In the future, this might perhaps be achieved with neutral endopeptidase inhibitors which interfere with the enzymatic degradation of ANP.

This work was supported by a grant of the Fonds National suisse de la Recherche Scientifique (FN no. 32-9269.87/3).

\section{References}

[1] Birkenhäger WH. Diuretics and blood pressure reduction: physiologic aspects. J Hypertens 1990; 8 (Suppl 2): S3-S7.

[2] Frohlich ED, Schnaper HW, Wilson IM, Fries ED. Haemodynamic alterations in hypertensive patients due to chlorothiazide. N Engl J Med 1960; 262: 1261-3.

[3] Conway J, Lauwers P. Haemodynamic and hypotensive effects of long-term therapy with chlorothiazide. Circulation 1967;22: $21-2$.

[4] Greven J, Heidenreich O. Diuretıc drugs in hypertension. In: van Zwieten PA, ed. Handbook of Hypertension, Vol. 3: Pharmacology of Antihypertensive Drugs. Amsterdam-New York-Oxford: Elsevier Science Publishers, B.V, 1984: 66-101.

[5] Philipp TH, Distler A. Diuretika und Gefässreagibilität. In: Rosenthal J, Knauf H, eds. Diuretika. Weinheim Edition Medizin, 1980: 60.

[6] Blantz RC, Gabba1 FB. Effect of angiotensin Il on glomerular hemodynamic and ultrafiltration coefficient. Kid Int 1987; 31 (Suppl 20): S108-S111.

[7] Myers BD, Deen WM, Brenner BM. Effects of norepinephrine and angiotensin II on the determinants of glomerular ultrafiltration and proximal tubule fluid reabsorption in the rat. Circ Res 1975; 37: 101-10.

[8] Blantz RC, Konnen KS, Tucker BJ. Angiotensin II effects upon the glomerular microcirculation and ultrafiltration coefficient of the rat. J Clin Invest 1976; 57: 419-34.

[9] Biollaz J, Nussberger J, Porchet $M$ et al. Four-hour infusion of synthetic atrial natriuretic peptide in normal volunteers. Hypertension 1986; 8 (Suppl 2): 96-105.

[10] Weidmann P, Gnãdinger MP, Ziswiler $\mathrm{HR}$ et al. Cardiovascular, endocrine and renal effects of atrial natriuretic peptide in essential hypertension. J. Hypertens 1986; 4 (Suppl 2): S71-S83.

[11] Kleinert HD, Maack T, Atlas et al. Atrial natriuretic factor inhibits angiotensin-, norepinephrine- and potassium-induced vascular contractility. Hypertension 1984; 6 (Suppl I): 143-7.

[12] Fluckiger JP, Waeber B, Matsueda GR, Delaloye B. et al. Effect of atriopeptin III on hematocrit and volemia of nephrectomized rats. Am J Physiol 1986; 251: H880-H883.

[13] Gavras H, Waeber B, Kershaw GR et al. Role of reactive hyperreninemia in blood pressure changes induced by sodium depletion in patients with refractory hypertension. Hypertension 1981; 3: 441-7.

[14] Vaughan ED, Carey RM, Peach MJ et al. The renin response to diuretic. A limitation of antihypertensive potential. Circ Res. 1978; 42: 376-81.

[15] Mimran A, Jover B, Casellas D. Renal adaptation to sodium deprivation. Effect of captopril in the rat. Am J Med 1984; 76 (5B): 14-21

[16] Posternak L, Brunner HR, Gavras H, Brunner DB. Angiotensin II blockade in normal man: interaction of renin and sodium in maintaining blood pressure. Kidney Int 1977; 11: 197-203

[17] Hall JE, Guyton AC, Smith MJ, Coleman TG. Blood pressure and renal function during chronic changes in sodium intake: Role of angiotensin. Am J Physiol 1980; 239: F27I-F280.

[18] Francis GS, Siegel RM, Goldsmith SR et al. Acute vasoconstrictor response to intravenous furosemide in patients with chronic congestive heart failure. Ann Int Med 1985; 103: 1-6.

[19] Aisenbrey GA, Handelman WA, Arnold P el al. Vascular effects sof arginine vasopressin dunng fluid deprivation in the rat. J Clin Invest 1981; 67: 961-8. 
[20] Andrews CE, Brenner BM. Relative contributions of arginine vasopressin and angiotensin II to maintenance of systemic arterial pressure in the anaesthetized water-deprived rat. Circ Res 1981; 48: 254-8.

[21] Burnier M, Biollaz J, Brunner DB, Brunner HR. Blood pressure maintenance in awaked dehydrated rats: Role of the renin system, vasopressin and sympathetic activity. Am J Physiol 1983; 245: $\mathrm{H} 203-\mathrm{H} 209$.

[22] McVeigh G, Galloway D, Johnston D. The case for low dose diuretics in hypertension: comparison of low and conventional doses of cyclopenthiazide. $\mathrm{Br}$ Med J 1988; 297: 95-8.

[23] Carlsen JE, Kober L, Torp-Pedersen C, Johansen P. Relation between dose of bendrofluazide, antihypertensive effect, and adverse biochemical effects. Br Med J 1990; 300: 975-8.

[24] Jeunemaitre X, Chatellier G, Kreft-Joris C et al. Efficacy and tolerance of spironolactone in essential hypertension. Am J Cardiol 1987; 60: 820-5.

[25] Van Brummelen P, Man in't Veld AJ, Schalekamp MADH. Hemodynamic changes during long-term thiazide treatment of essentual hypertension in responders and non-responders. Clin Pharm Ther 1980; 27: 328-36.

[26] Van Brummelen P, Schalekamp MADH, DeGraeff J. Influence of sodium intake on hydrochlorothiazide induced by changes in blood pressure, serum electrolytes, renin and aldosterone in essential hypertension. Acta Med Scand 1978; 204: 151-7.

[27] Brunner HR, Gavras H, Waeber B. Enhancement by diuretics of the antihypertensive action of long-term angiotensin converting enzyme blockade. Clin Exp Hypertens 1980; 2: 639-57.

[28] Thind GS, Mahapatra RK, Johnson A, Coleman RD. Lowdose captopril administration in patients with moderate-tosevere hypertension treated with diuretics. Circulation 1983; 67: $1340-5$.

[29] Cleland JGF, Gillen G, Dargie HJ. The effects of furosemide and angiotensin-converting enzyme inhibitors and their combination on cardiac and renal haemodynamics in heart failure. Euro Heart J 1988; 9: 132-41.

[30] Flapan AD, Davies E, Waugh $C$ et al. Acute administration of captopril lowers the natriuretic and diuretic response to a loop diuretic in patients with chronic cardiac failure. Eur Heart J 1991; 12: 924-7.

[31] Dzau V. Role of endothelium-derived vasoactive substances in the regulation of vascular tone via structural remodeling of blood vessels. In: Ryan US, Rubany GM, eds. Endothelial Regulation of Vascular Tone. New York, Basel, Hong Kong: Marcel Dekker Inc, 1991: 331-41.

[32] Moser $M$, Setaro JF. Antihypertensive drug therapy and regression of left ventricular hypertrophy: a review with a focus on diuretics. Eur Heart J 1991; 12: 1034-9.

[33] Brater DC. Resistance to diuretics: Emphasis on a pharmacological perspective. Drugs 1981; 22: 477-94.
[34] Schrier RW. Pathogenesis of sodium and water retention in high-output and low-output cardiac failure, nephrotic syndrome, cirrhosis, and pregnancy (First of two parts). N Engl J Med 1988; 319: 1065-72.

[35] Dzau WJ, Hollenberg NK. Renal response to captopril in severe heart failure: role of furosemide in natriuresis and reversal of hyponatremia. Ann Int Med 1984; 100: 777-82.

[36] Packer M, Medina N, Yushak M. Correction of dilutional hyponatremia in severe chronic heart failure by converting enzyme inhibition. Ann Int Med 1984; 100: 782-9.

[37] Millar JA, McLean KA, Summer DJ, Reid JL. The effects of the calcium antagonist nitrendipine on pressor and aldosterone responses to angiotensin II in normal man. Eur $\mathbf{J}$ Clin Pharmacol 1983; 24: 315-21.

[38] Guthrie GP, McAllister RG, Kotchen TA. Effects of intravenous and oral verapamil upon pressor and adrenal steroidogenic responses in normal man. J Clin Endocrinol Metab 1983; 57: $339-43$

[39] Wilcox CS, Loon NR, Ameer B, Limacher M. Renal and hemodynamic responses to bumetanide in hypertension: effects of nitrendipine. Kidney Int 1989; 36: 719-25.

[40] Northridge DB, Jardine AG, Alabaster CT et al. Effect of UK 69578: a novel atriopeptidase inhibitor. Lancet 1989; 2: 591-3.

[41] Seymour AA, Fennell SA, Swerdel JN. Potentiation of renal effects of atrial natriuretic factor $-(99-126)$ by SQ 29071. Hypertension 1989; 14: 87-97.

[42] Chipkin RE, Berger JG, Billard W et al. Pharmacology of SCH 34826 , an orally active enkephalinase inhibitor analgesic. J Pharmacol Exp Ther 1988; 245: 829-38.

[43] Sybertz EJ, Chiu PJS, Vemulapalli S et al. Atrial natriuretic factor-potentiating and antihypertensive activity of $\mathrm{SCH}$ 34826 , an orally active neutral metalloendopeptidase inhibitor. Hypertension 1990; 15: 152-61.

[44] Richards M, Espiner E, Frampton C et al. Inhibition of endopeptidase EC 24.11 in human. Renal and endocrine effects. Hypertension 1990; 16: 269-76.

[45] Burnier M, Ganslmayer M, Perret F et al. Effects of SCH 34826, an orally active inhibitor of atrial natriuretic peptide degradation, in healthy volunteers. Clin Pharmacol Ther 1991; 50: $181-91$.

[46] Richards AM, Witter G, Espiner EA et al. Prolonged inhibition of endopeptidase 24.11 in normal man: renal, endocrine and haemodynamic effects. J Hypertens 1991; 9: 955-62.

[47] Dussaule JC, Grange D, Wolf JP et al. Effect of sinorphan, an enkephalinase inhibitor, on plasma atrial natriuretic factor and sodium urinary excretion in cirrhotic patients with ascites. J Clin Endocrinol Metab 1991; 72: 653-9.

[48] Kahn JC, Patey M, Dubois-Rande JL et al. Effect of sinorphan on plasma atrial natriuretic factor in congestive heart failure. Lancet 1990; II: 118-9. 